\title{
AVALIAÇÃO FÍSICO-QUÍMICA, MICROBIOLÓGICA E MACROSCÓPICA DO GELO COMERCIALIZADO NO MUNICÍPIO DE TERESINA-PI
}

\author{
Evaluation physico-chemical, microbiological and macroscopic ice merchantable in \\ Teresina-PI
}

Lisandra Maria da Silva Carvalho ${ }^{1}$

Edison Araújo de Oliveira²

RESUMO: O gelo é um alimento como outro qualquer que ingerimos, portanto, exige os mesmos cuidados que cercam a produção de quaisquer alimentos e se fabricado sob más condições sanitárias pode afetar diretamente a saúde dos consumidores. Este trabalho objetivou avaliar a qualidade físico-química, microbiológica e macroscópica do gelo comercializado no município de Teresina-PI. A análise físicoquímica de $\mathrm{pH}$, cloro residual livre, cloretos, amônia, dureza total e turbidez e a análise microbiológica (NMP) foram realizadas de acordo com o Manual Prático de Análises de Águas (BRASIL, 2006). A determinação de sujidades leves ocorreu através da análise macroscópica de acordo com o Instituto Adolfo Lutz (1985) e a análise estatística por meio da análise de variância (ANOVA), médias e desvios padrões (VIEIRA, 1999). Os resultados obtidos das análises físico-químicas e microbiológicas das marcas de gelo avaliadas se apresentaram de acordo com os padrões de potabilidade exigidos para água de consumo humano e a análise macroscópica apresentou sujidades leves para as três marcas, onde 50\% foram verificados para a marca $C$ e $25 \%$ para as marcas $A$ e $B$, mostrando um produto impróprio para o consumo humano por apresentar material prejudicial (perigo físico) à saúde dos consumidores de acordo legislação vigente.

Palavras-chave: Gelo. Análise. Físico-Química. Microbiológica e Macroscópica.

ABSTRACT: Ice is a food we eat like any other, therefore requires the same care that surround the production of any food and are manufactured under poor sanitary conditions could directly affect the health of consumers. This work aimed to evaluate the physico-chemical, microbiological and macroscopic ice sold in the city of

\footnotetext{
${ }^{1}$ Graduada em Licenciatura em Química pela UFPI. Graduada em Bacharelado em Química com Atribuições Tecnológicas pela UFPI. Graduada em Tecnologia de Alimentos pelo IFPI. Especialista em Docência do Ensino Superior pela UESPI. Especialista em Controle de Qualidade em Alimentos pelo IFPI. Mestra em Química pela UFMA. Integrante do Grupo de Estudos e Pesquisas Formação de Professores e Culturas da/na Escola - FOPROCE do Instituto Federal do Maranhão / Campus Zé Doca. Professora do Ensino Básico, Técnico e Tecnológico do Instituto Federal do Maranhão / Campus Zé Doca.

${ }^{2}$ Graduando em Licenciatura em Química pelo Instituto Federal do Maranhão / Campus Zé Doca. Integrante do Grupo de Estudos e Pesquisas Formação de Professores e Culturas da/na Escola FOPROCE do Instituto Federal do Maranhão / Campus Zé Doca.
} 
Teresina-PI. The physical-chemical analysis of $\mathrm{pH}$, free residual chlorine, chlorides, ammonia, total hardness and turbidity and microbiological analysis (NMP) was performed according to the Practical Handbook of Water Analysis (BRAZIL, 2006). The determination of light filth was performed by macroscopic analysis according to the Institute Adolfo Lutz (1985) and statistical analysis was performed using analysis of variance, means and standard deviations (VIEIRA, 1999). The results of physicochemical and microbiological evaluated brands of ice is presented in accordance with the standards for potable drinking water and the macroscopic analysis showed light filth for the three brands, where $50 \%$ was found for the brand, and C $25 \%$ for brands a and $\mathrm{B}$, showing a product unfit for human consumption by presenting material harmful to consumers under current law.

Keywords: Ice. Analysis. Physical-Chemical. Microbiological and Macroscopic.

\section{INTRODUÇÃO}

$\mathrm{O}$ uso de gelo industrializado para consumo humano e para refrigerar e conservar alimentos é prática comum e pode apresentar contaminantes físicos, químicos e microbiológicos. Contendo assim, microrganismos patogênicos se feito com água de má qualidade, equipamentos contaminados ou manuseados em condição péssima de higiene, existindo o risco potencial da transmissão de doenças de veiculação hídrica (PAWSEY; HOWARD, 2001).

A população e as indústrias alimentícias apresentam um consumo elevado de gelo por dia, tendo um aumento na época do verão (MENDES, 2009). Utilizado para o consumo direto e para a conservação de alimentos o gelo pode ser um importante veículo de contaminação microbiana, sendo que, no Brasil, já se observou a baixa qualidade do gelo utilizado na refrigeração, devido à presença de grandes quantidades de microrganismos (PIMENTEL, 2001).

Conforme Vieira (2004), mesmo não oferecendo condições de multiplicação às bactérias, o gelo contaminado pode atuar como veículo de microrganismos e pode ainda estar sujeito à contaminação por materiais estranhos como: pedras, insetos ou fragmentos, folhas, entre outros. A fabricação do gelo deve seguir a Resolução RDC n. 274 de 2005, que aprova o "regulamento técnico para águas envasadas e gelo" e define o gelo para consumo humano como a água em estado sólido (BRASIL, 2005). 
A principal matéria-prima para o gelo é a água, e esta tem que ser devidamente tratada, filtrada, visando atingir os patamares requeridos pela legislação inerente à produção de gelo e para uso humano, que deverá ser preparada, segundo os parâmetros microbiológicos, químicos e radioativos que atendam à Norma de Qualidade de Água para Consumo Humano (BRASIL, 2011).

A água quando não potável, pode causar várias doenças ao ser humano. Portanto, há uma importância da qualidade do gelo, traduzida na adoção de rigorosas práticas higiênicas em sua fabricação, manuseio, embalagem, conservação e distribuição (FREIRE, et al., 2008). Diversos trabalhos têm demonstrado que o gelo comercializado apresenta qualidade variável e às vezes pode colocar em risco a saúde dos consumidores (PIMENTEL; PANETTA, 2003).

Dentro do exposto, e percebendo que muitas vezes o gelo utilizado na conservação de alimentos apresenta qualidade insatisfatória, como pode ser verificado em diversos trabalhos descritos na literatura científica (NICHOLS etal., 2000; LATEEF et al., 2006),esta pesquisa avaliou a qualidade físico-química, microbiológica e macroscópica do gelo comercializado no município de Teresina-PI de acordo com os padrões vigentes.

\section{MATERIAIS E MÉTODOS}

\subsection{Amostragem}

Foram coletadas e analisadas 6 (seis) amostras de 3 (três) marcas diferentes de gelo embalado comercialmente, obtidas em 3 (três) diferentes estabelecimentos comerciais do município de Teresina-PI.

As amostras foram transportadas em caixas isotérmicas, devidamente lavadas, secas e esterilizadas, até o Laboratório de Alimentos do Instituto Federal de Educação, Ciência e Tecnologia do Piauí-IFPI e permaneceu sob refrigeração a $5 \stackrel{\circ}{ } \mathrm{C}$ até o descongelamento para então serem submetidas às análises físico-químicas, microbiologia e macroscópicas realizadas em triplicatas e a precisão através de repetibilidade (BRASIL, 2006).

\section{PARÂMETROS ANALISADOS}

\subsection{Físico-químicos}


As análises físico-químicas de $\mathrm{pH}$, cloro residual livre, cloretos, amônia, dureza e turbidez foram realizadas segundo a metodologia do Manual Prático de Análise de Água (BRASIL, 2006).

$\mathrm{O} \mathrm{pH}$ foi determinado pelo método potenciométrico, utilizando-se um pHmetro de bancada (MPA-210), a turbidez pela utilização de turbidímetro de bancada (Tecnopon versão 3.9), o teor de cloro residual livre e de amônia foram realizados usando respectivamente Kits colorimétricos portátil, Genkit $\mathrm{Cl} / \mathrm{pH}$ e Ecokit-alfakit sênior, o teor de cloreto pelo método de Mohr usando solução padrão de $\mathrm{AgNO}_{3}$ na presença de cromato de potássio e a determinação da dureza total pelo método volumétrico complexiométrico usando uma solução padrão de EDTA na presença de Negro de Ericromo T.

\subsection{Microbiológico}

As análises microbiológicas para coliformes totais e termotolerantes foram realizadas de acordo com a metodologia utilizada no Manual de Métodos de Análises Microbiológicas de Água (SILVA, 2005) e foram determinadas através da técnica dos tubos múltiplos (NMP). O ensaio presuntivo para coliformes consistiu no enriquecimento seletivo de $100 \mathrm{ml}$ das amostras em $50 \mathrm{ml}$ de Caldo PA incubado a $35^{\circ} \mathrm{C} / 24 \mathrm{~h}-48 \mathrm{~h}$.

Para pesquisa de coliformes totais, uma alçada de cada amostra enriquecida foi inoculada em tubos contendo Caldo Lactosado Verde Brilhante Bile 2\% e incubadas a $35{ }^{\circ} \mathrm{C} / 24 \mathrm{~h}-48 \mathrm{~h}$, enquanto os coliformes termotolerantes em caldo EC a $44,5 \stackrel{\circ}{ } \mathrm{C}$ por 24 horas. Os resultados foram expressos em NMP (número mais provável de coliformes por $100 \mathrm{ml}$ da amostra).

\subsection{Macro e microscópica}

Para a determinação de materiais estranhos ao nível macroscópico (sujidades leves), a avaliação foi realizada através do método de análise direta (ou análise macroscópica) de acordo com o Instituto Adolfo Lutz (1985). A amostra é espalhada em uma camada fina em um fundo contrastante e realizando uma observação direta 
para verificar a presença de matérias macroscópicas prejudiciais à saúde. Quando necessário foi utilizado o microscópio óptico para confirmar a estrutura da sujidade encontrada.

\subsection{Análise estatística}

Para análise estatística foi utilizado o delineamento inteiramente casualizado para a realização da amostra. A análise dos resultados foi realizada por meio da análise de variância (ANOVA) e calculada as médias e os desvios padrões (VIEIRA, 1999).

\section{RESULTADOS E DISCUSSÃO}

\subsection{Análises físico-químicas}

Na Tabela 1, estão apresentados os resultados das análises físico-químicas.

Tabela 1. Análises físico-químicas (valores médios e desvios padrões) encontradas em amostras comerciais de gelo em Teresina-PI.

\begin{tabular}{|c|c|c|c|c|}
\hline \multirow[t]{2}{*}{ Parâmetros } & \multicolumn{3}{|c|}{ Marcas de Gelo } & \multirow{2}{*}{$\begin{array}{l}\text { Legislação } \\
\text { (BRASIL, 2011) } \\
\text { VMP }^{1}\end{array}$} \\
\hline & $\begin{array}{l}A \\
(X \pm S)^{2}\end{array}$ & $\begin{array}{l}B \\
(X \pm S)\end{array}$ & $\begin{array}{l}C \\
(X \pm S)\end{array}$ & \\
\hline $\mathrm{pH}$ & $7,0 \pm 0,30$ & $7,0 \pm 0,53$ & $7,0 \pm 0,31$ & 6,0 a 9,5 \\
\hline $\begin{array}{l}\text { Cloro residual } \\
\text { livre }(\mathrm{mg} / \mathrm{L})\end{array}$ & $0,5 \pm 0,0$ & $0,5 \pm 0,0$ & $0,5 \pm 0,0$ & 5 \\
\hline Cloreto (mg/L) & $0,08 \pm 0,01$ & $0,07 \pm 0,02$ & $0,07 \pm 0,02$ & 250 \\
\hline Amônia(mg/L) & $0,25 \pm 0,0$ & $0,37 \pm 0,18$ & $0,63 \pm 0,53$ & 1,5 \\
\hline Dureza (mg/L) & $42,7 \pm 2,67$ & $39,7 \pm 3,50$ & $39,7 \pm 3,23$ & 500 \\
\hline Turbidez (UT) & $0,9 \pm 0,24$ & $1,2 \pm 0,51$ & $1,4 \pm 0,42$ & 5 \\
\hline
\end{tabular}

(1) valor máximo permitido; (2) média e desvio padrão.

As análises físico-químicas, de todas as marcas comercializadas estão de acordo com o valor máximo permitido, estabelecido pela Legislação, para qualidade da água para consumo humano e seu padrão de potabilidade (BRASIL, 2011). 
No presente trabalho os valores de $\mathrm{pH}$ obtidos não apresentou variação e estando em concordância com os valores recomendados para amostras de água potável $(6,0$ - 9,5), atendendo a legislação vigente. Diferente dos trabalhos realizados por Moyeret al., (1993) que encontrou, em seu estudo com gelo comercializado em pacotes, amostras cujo $\mathrm{pH}$ variou entre 4,75 e 9,8, sendo que apenas cinco amostras atendiam a legislação vigente. E em relação a Pimentel e Panetta (2003) que observaram pH entre 4,88 e 6,98, notando que os resultados obtidos podiam favorecer a multiplicação bacteriana em sua pesquisa com gelo. Também em suas pesquisas Serrano e Sousa (2008) encontraram pH em desacordo com a legislação.

Após a desinfecção, a água deve conter um teor mínimo de cloro residual livre de $0,5 \mathrm{mg} / \mathrm{L}$, sendo obrigatório a manutenção de, no mínimo $0,2 \mathrm{mg} / \mathrm{L}$ em qualquer ponto da rede de distribuição conforme Legislação (BRASIL, 2011). Os resultados obtidos neste trabalho mostraram valores iguais ao valor mínimo permitido, que pode ser relacionada com ocorrência de vazamentos nas operações de manutenção das tubulações, as quais dão origem a contaminações que reduzem o teor de cloro na rede. Também podem advir de problemas relacionados com deficiências nas técnicas de medição do cloro residual livre, tanto por falha do operador quanto do equipamento de medida (VIEIRA, 1997).

Segundo Queiroga, et al. (2007) a presença de cloro residual livre na água assegura a sua qualidade bacteriológica e autores como Serrano e Sousa (2008) em seu trabalho relataram que 29 (96,6\%) amostras estão em desacordo quanto ao teor de cloro residual, indicando que há riscos ao produto armazenado, bem como à população consumidora.

Os valores encontrados para cloretos estão de acordo com os padrões de potabilidade, no entanto, apresentaram-se abaixo do valor máximo permitido, entre 0,07 e $0,08 \mathrm{mg} / \mathrm{L}$, isso se deve ao fato de que são removidos por evaporação (MACEDO, 2007).

Em estudo similar, Bomfim et al. (2007) verificaram em seu trabalho que todas as amostras de água analisadas estavam de acordo com a legislação, não acarretando, portanto, os efeitos indesejáveis, como sabor desagradável e efeito laxativo que quantidades elevadas do constituinte podem ocasionar.

Observando os valores obtidos pela determinação de amônia percebeu-se números extremamente positivos nas amostras analisadas, visto que os intervalos 
de variação para a mesma foram de 0,25 a 0,63 mg/L. O resultado corrobora com Macedo (2007) que mostra que altas concentrações de amônia indica fontes de poluição próxima ou recente.

A dureza total para $100 \%$ das amostras avaliadas foi inferior a $500 \mathrm{mg} / \mathrm{L} \mathrm{em}$ termos de $\mathrm{CaCO}_{3}$, que é o valor máximo preconizado pela legislação. As mesmas são classificadas de acordo com Macedo (2007), como água mole, por apresentar dureza $<50 \mathrm{mg} / \mathrm{L}$ e estando de acordo com os padrões vigentes. Quanto à qualidade das águas investigadas para fins de consumo humano, não existe, até o presente, evidências de que a dureza produza transtorno de ordem sanitária, ao contrário, alguns estudos sinalizam para uma menor incidência de doenças cardíacas em áreas onde as águas apresentam maior dureza (VON SPERLING, 1996).

Nos resultados encontrados para a avaliação da turbidez observou-se uma pequena variação entre as amostras de 0,9 a 1,4 UT. A legislação estipula como limite máximo o valor de 5 UT para turbidez. Portanto, as amostras apresentaram valores inferiores ao valor máximo preconizado pela legislação, mas que se encontram dentro das normas vigentes (BRASIL, 2011) e esse parâmetro não apresentou valores que pudessem representar algum problema com relação à qualidade da água consumida.

A presença de partículas (turbidez) provoca a dispersão e a absorção da luz, deixando a água com aparência nebulosa, esteticamente indesejável e potencialmente perigosa (MACEDO, 2007).

\subsection{Análise microbiológica}

$\mathrm{Na}$ Tabela 2, se encontra apresentados os resultados da análise microbiológica.

Tabela 2. Avaliação microbiológica em amostras comerciais de gelo em Teresina-PI.

\begin{tabular}{llll}
\hline Parâmetro & $\begin{array}{l}\text { Marcas de } \\
\text { Gelo }\end{array}$ & $\begin{array}{l}\text { Legislação } \\
\text { (BRASIL, } \\
2005) \\
\text { NMP/100 mL }\end{array}$ \\
\hline A & B & C & \\
\hline
\end{tabular}




\begin{tabular}{|c|c|c|c|c|}
\hline Coliformes totais $/ 100 \mathrm{~mL}$ & Ausente & Ausente & Ausente & Ausência \\
\hline $\begin{array}{l}\text { Coliformes } \\
\text { termotolerantes } / 100 \mathrm{~mL}\end{array}$ & Ausente & Ausente & Ausente & Ausência \\
\hline
\end{tabular}

As análises microbiológicas revelaram que todas as amostras avaliadas estão isentas de microrganismo, tanto para coliformes totais quanto para termotolerantes (média do NMP $<1,1 / 100 \mathrm{~mL}$ ), estando de acordo com a legislação. Estudos mostram que a cloração diminuiu a presença de bactérias, principalmente coliformes totais e termotolerantes, além de evidenciar ausência de detecção da Salmonellasp., quando os níveis de cloro livre apresentam-se superiores a 0,1 mg/L (ARAÚJO et al., 2011).

Como o teor de cloro analisado neste trabalho apresentou-se um valor maior que $0,1 \mathrm{mg} / \mathrm{lverificou}$ que a concentração do mesmo foi suficiente para a desinfecção da água e com isso a ausência de coliformes totais e termotolerantes. $O$ cloro é o produto mais utilizado na desinfecção da água, sendo a sua presença em concentração suficiente é fundamental como agente bactericida (MACEDO, 2007).

No entanto, em outro estudo, foram encontradas 29 (96,7\%) amostras positivas para coliformes totais e $22(73,3 \%)$ para termotolerantes e ressaltaram que o gelo não deve conter nenhuma substância que possa ser perigosa para a saúde, obedecendo ao padrão de água potável (GIAMPIETRO; REZENDE-LAGO, 2009). Já Veiraet al., (1997) obteve 19 (24,3\%) amostras positivas para coliformes termotolerantes o que levou a suspeita de que água não clorada foi utilizada ou que houve contaminação do gelo após sua saída da fábrica.

\subsection{Análise macro e microscópica}

Os resultados da contagem de sujidades leves realizada estão dispostos na Tabela 3.

Tabela 3. Número de sujidades e insetos encontrados em amostras comerciais de geloem TeresinaPI.

\begin{tabular}{lll}
\hline Marcas de gelo & $\begin{array}{l}\text { Número } \\
\text { sujidades/amostra }\end{array}$ & $\begin{array}{l}\text { démero de insetos ou } \\
\text { partes } \\
\text { insetos/amostra }\end{array}$ \\
\hline A & 1 & 0
\end{tabular}




\begin{tabular}{lll} 
B & 1 & 0 \\
C & 1 & 1 \\
\hline
\end{tabular}

Resolução - RDC n.ำ 175.

Dentre as marcas analisadas, observou-se que a marca $C$ foi a que apresentou o maior número de sujidades (50\%), detendo quase a metade do total de sujidades encontradas, sendo a única amostra a apresentar insetos inteiros. As marcas A e B, apesar de não apresentar insetos ou partes destes, não se mostraram totalmente livre de sujidades apresentando pedaços de plásticos e fiapos e detiveram cada uma $25 \%$ das sujidades encontradas, portanto, as mais indicadas para consumo, com menor risco físico para o consumidor (FONTES, E., 2003) (FONTES, P., 2003). A Figura 1 ilustra algumas das sujidades leves encontradas nas amostras de gelos. E a figura 2 mostra um inseto inteiro.

Figura 1. Sujidades leves encontradas nas amostras de gelo (marcas A, B e C).
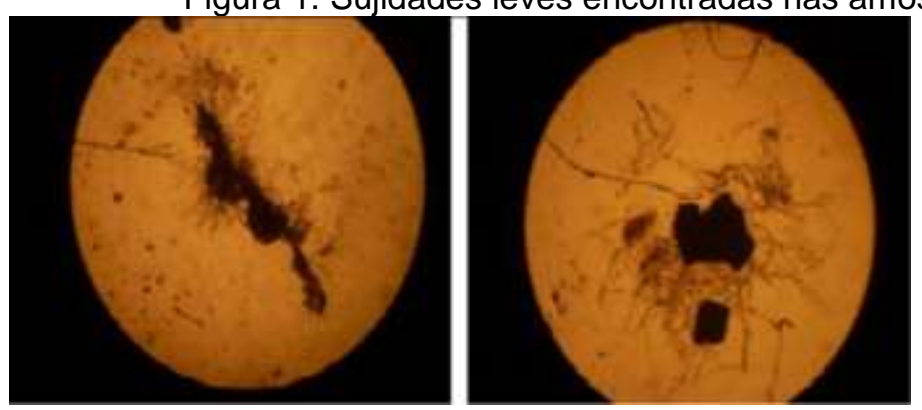

Fonte: Próprios Autores.

Figura 2. Inseto encontrado na amostra de gelo (marca C) em Teresina - PI.

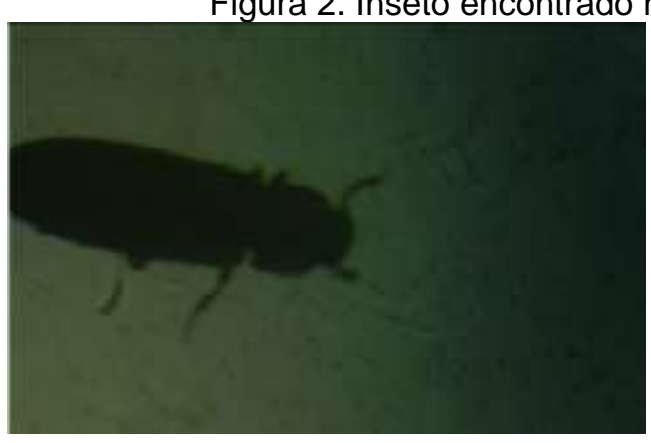

Fonte: Próprios Autores.

A maior parte das sujidades encontradas nesta pesquisa é constituída de materiais como fiapo, pedaço de plásticos e inseto, o que indica falha durante 0 envase, estocagem inadequada e transporte do gelo. Os manipuladores de alimentos, bem como o manuseio ou acondicionamento incorreto do gelo, estão 
entre os principais parâmetros responsáveis pela sua contaminação por sujidades devido à falta de orientação quanto às Boas Práticas de Fabricação (BRASIL, 1997).

\section{CONCLUSÕES}

Em face dos resultados obtidos pode-se concluir que 100\% das amostras de gelo analisadas foram consideradas próprias para o consumo humano, de acordo com os padrões físico-químicos e microbiológicos da legislação brasileira (BRASIL, 2005).

Já em acordo com a Resolução - RDC n. 175, de 08 de julho de 2003, que regulamenta a avaliação de matérias macroscópicas e microscópicas prejudiciais à saúde humana em alimentos embalados, as amostras de gelo analisadas apresentaram como impróprias para o consumo humano por apresentar material prejudicial à saúde dos consumidores.

Embora a legislação preconize a ausência de sujidades, parasitos e larvas (BRASIL, 2005), não há como encontrar produtos no mercado totalmente livre das mesmas, logo, a solução é analisar o grau de periculosidade dessas sujidades e avaliar o quanto elas podem lesar a saúde dos consumidores, assim como, maior fiscalização nas indústrias fabricantes de gelo, no transporte e armazenamento do mesmo.

\section{REFERÊNCIAS}

ARAÚJO, G.; ARAÚJO, F. R.; ALVES, R. I. S.; TONANI, K. A. A.; RAGAZZI, M. F.; JULIÃO, F. C. et al. Qualidade físico-química e microbiológica da água para o consumo humano e a relação com a saúde: estudo em uma comunidade rural no estado de São Paulo. In: O Mundo da Saúde, São Paulo, 2011. 104 p.

BOMFIM, M. V. J.; SOEIRO, G. O.; MADEIRA, M.; BARROS, H. D. Avaliação físicoquímica e microbiológica da água de abastecimento do laboratório de bromatologia da UERJ. In: Revista Higiene Alimentar, São Paulo, n. 152. v. 21, pp. 99-103, 2007.

BRASIL. Ministério da Saúde. Portaria SVS/MS n. 326 de 30 de julho de 1997. Regulamento técnico sobre as condições higiênico-sanitárias e de boas práticas de fabricação para estabelecimentos produtores/industrializadores de alimentos. Diário Oficial da República Federativa do Brasil, Poder Executivo, Brasília, DF, 01 ago. 1997. 
BRASIL. Agência Nacional de Vigilância Sanitária. RDC n‥ 175, de 08 de julho de 2003. Aprova o "Regulamento Técnico de Avaliação de Matérias Macroscópicas e Microscópicas Prejudiciais à Saúde Humana em Alimentos Embalados”. Agência Nacional de Vigilância Sanitária, 2003.

BRASIL. Agência Nacional de Vigilância Sanitária. RDC n‥ 274, de 22 de setembro de 2005. Aprova o "Regulamento Técnico para Águas Envasadas e Gelo". Agência Nacional de Vigilância Sanitária, 2005.

BRASIL. Fundação Nacional de Saúde. Manual prático de análise de água. 2.ed. rev. Brasília: Fundação Nacional de Saúde,2006. p. 146.

BRASIL. Ministério da Saúde. Portaria no. 2914 de 12 de dezembro de 2011. Dispõe sobre os procedimentos de controle e de vigilância da qualidade da água para consumo humano e seu padrão de potabilidade. Brasília: Ministério da Saúde, 2011.

FONTES, E. A. F.; FONTES, P. R. Microscopia de alimento: fundamentos teóricos. Viçosa: Editora UFV. 2005.

FREIRE, A. J.; ASSUNÇÃO, G. M.; ARAÚJO J. C.; BARIN, C. S. Análise físicoquímica e microbiológica de gelo comercializado em postos de combustível. Londrina. FURB, Novembro de 2008.

GIAMPIETRO, A.; REZENDE - LAGO, N. C. M., Qualidade do gelo utilizado na conservação de pescado fresco. In: Arquivo do Instituto Biológico, São Paulo, n. 3. v. 76 , pp. $505-508,2009$.

INSTITUTO ADOLFO LUTZ. Normas analíticas do Instituto Adolfo Lutz: Métodos químicos e físicos para análises de alimentos. 3. ed. Editora São Paulo. 1985.

LATEEF, A.; OLOKE, J.K.; KANA, E.B.G.; PACHECO, E. The microbiological quality of ice used to cool drinks and foods in Ogbomoso Metropolis, Southwest, Nigeria. In: Internet Journal of Food Safety, v. 8, p. 39-43, 2006.

MACÊDO, J. A. B. Águas \& Águas. Belo Horizonte - MG: CRQ-MG, 3.rev.2007.

MENDES, A. L. S. Qualidade microbiológica do gelo para consumo em bebidas um estudo nos estabelecimentos das zonas balneares do porto, Porto, Maio de 2009. 123 f. Dissertação apresentada para obtenção do grau de mestre em Saúde Pública, Universidade do Porto, 2009.

MOYER, N. P.; BREUER, G. M.; HALL, N. H.; KEMPF, J. L.; FRIELL, L. A.; RONALD, G.W.; HAUSLER, W. J. Quality of packaged ice purchased at retail establishments in lowa. In: Journal of Food Protection, v.56, pp. 426-431, 1993.

NICHOLS, G.; GILLESPIE, I.; LOUVOIS, J. The microbiological quality of ice used to cool drinks and ready-to-eat food from retail and catering premises in the United Kingdon. In: Journal of Food Protection, n. 1. v.63, pp. 78-82, 2000. 
PAWSEY, R. K.; HOWARD, P. Drinking ice as a vector of gastrointestinal diseases. In: British FoodJournal, n. 4. v.103, pp. 253-263, 2001.

PIMENTEL, L. P. S. Características físico-químicas e microbiológicas do gelo utilizado na conservação do pescado comercializado em supermercados da Grande São Paulo, Brasil. 1999. 2001. 72f. Dissertação apresentada para obtenção do grau de mestre em Prática de Saúde Pública, Universidade de São Paulo, São Paulo, 2001.

PIMENTEL, L. P. S.; PANETTA, J. C. Condições higiênicas do gelo utilizado na conservação de pescado comercializado em supermercados na Grande São Paulo. Parte 2, resultados físico - químicos. In: Revista Higiene Alimentar, São Paulo, n. 106. v. 17, p. 64-71, 2003.

QUEIROGA, I.; SANTOS, C.; CARNEIRO, L. Ocorrência de Coliformes Totais na Presença de Cloro Residual Mínimo no e Distribuição Público de Água Potável da Cidade de Abadia Goiás. New Lab, Goiás, 2007. 83 p.

SERRANO N. F. G.; SOUSA C. P. Incidência de Coliformes, Staphylococcuscoagulase positivo e Pseudomonas spp. em gelo produzido e comercializado na cidade de São Carlos - SP. Universidade Federal de São Carlos, Centro de Ciências Biológicas e da Saúde, Departamento de Enfermagem, Departamento de Morfologia e Patologia. 2008.

SILVA, N. D. Manual de métodos de análise microbiológica de água. São. Paulo: Livraria Varela, 2005.

VIEIRA, P.; COELHO, S.; PRAÇA, P. Controle de Cloro em Sistemas de transporte e distribuição de Água. NACE et al., 1997.

VIEIRA, S. Elementos de Estatística. São Paulo: Ed. Atlas, 1999.

VIEIRA, R. H. S. Microbiologia, higiene e qualidade do pescado: teoria e prática. São Paulo: Varela, 2004. p. 380.

VON SPERLING, M. Introdução à qualidade das águas e ao tratamento de esgotos. Belo Horizonte: Departamento de Engenharia Sanitária e Ambiental, Un. Federal de Minas Gerais, 1996. p. 243. 